\title{
CUSTOMIZE ANTARMUKA SEBAGAI SALAH SATU ALTERNATIF PEMBATASAN HAK AKSES STUDI KASUS SISTEM INFORMASI KLINIK KECANTIKAN
} (Customize Interface as an Alternative One Access Rights Restrictions Clinical Information Systems Case Study Beauty)

\author{
Whisnumurti Adhiwibowo \\ Fakultas Teknologi Informasi dan Komunikasi Universitas Semarang
}

\begin{abstract}
Business growth is more rapid in Semarang city this decade, particularly for the beauty clinic. Emergence of a new beauty clinic creates fierce competition among the existing beauty clinics therefore it requires a standard of service, advertising/promotion, the strategic location of the clinic, and specificity/characterization of the clinic's own beauty.

One main point to note in this regard is the service. Service is one of the supporting factors that is very important in supporting and improving customer satisfaction scores. In service , the effectiveness of the process and the user access consider as significant factors. So the need of the accurate system is required.

To meet these needs, I will design an interface system that will facilitate the convergence of the user access restrictions. It is in a custom interface model that will be done using a prototype model of software engineering.
\end{abstract}

Keyword : Interface, Prototype dan User access restriction

\section{Pendahuluan}

Perkembangan bisnis klinik kecantikan dalam dasawarsa ini semakin pesat di kota Semarang. Banyaknya pelayanan jasa akan kecantikan, menciptakan persaingan yang ketat antara klinik kecantikan yang ada. Salah satu point utama yang membutuhkan perhatian dalam persaingan bisnis jasa kecantikan adalah pelayanan. Kecepatan dan kemudahan dalam transaksi dan administrasi merupakan salah satu nilai yang harus diperhatikan dalam penyelenggaraan usaha berbasis pelayanan. Untuk itu dibutuhkan dukungan sistem yang tepat yang dapat menjembatani kebutuhan tersebut.

Untuk memenuhi kebutuhan klinik kecantikan yang beraneka ragam proses bisnisnya, dibutuhkan suatu jenis produk yang dapat memberikan gambaran sistem klinik secara umum. Pembangunan sistem tersebut, dapat menggunakan pemodelan Prototipe Evalusioner yang dibangun berdasarkan kebutuhan dan pemahaman secara umum. Prototipe yang ada dapat dikembangkan dan dievolusikan sesuai dengan permintaan dari customer. Dengan pemodelan prototipe diharapkan customer akan mendapatkan gambaran awal secara umum akan sistem yang akan dibangun sehingga akan mempermudah dalam perancangan sistem.

Penggunaan pemodelan prototipe, dimaksudkan untuk mempermudah customer dalam memilih dan menentukan prioritas kebutuhan klinik, yang dapat dilihat atau ditampilkan dalam antarmuka prototipe produk. Selain mempermudah customer, pemodelan prototipe dengan memberikan banyak custom menu dalam antarmuka, akan memberikan pilihan/gambaran/ilustrasi menu kepada kebutuhan customer baik dari tingkat manajemen hingga operasional. Dengan demikian diharapkan customer dapat memilah kebutuhan untuk tiap-tiap user yang mengakses sistem. Selain hal tersebut, 
pemilihan custom menu memiliki tujuan utama yaitu untuk memberikan batasan akses menu kepada tiap-tiap user pengguna. Pembatasan ini diberlakukan karena banyaknya user dengan jabatan atau fungsi yang berbeda dalam klinik agar tidak terjadi tumpang tindih pekerjaan.

\section{Metode}

Dalam perancangan sistem ini akan dibangun suatu sistem antarmuka, yang dapat di custom sesuai jabatan atau fungsi tiap-tiap user. Dalam perancangan sistem ini dibutuhkan perangkat keras dan perangkat lunak. Model perancangan yang digunakan menggunakan model two tier.

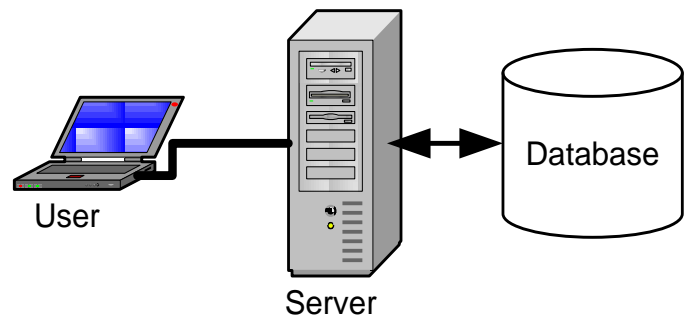

Gambar 1. Model Two Tier

\subsection{Perangkat Keras}

Spesifikasi perangkat keras yang digunakan untuk membangun sistem aplikasi klinik ini adalah

Server :

1. Inter Quard Core

2. RAM $4 \mathrm{~GB}$

3. Harddisk $250 \mathrm{~GB}$

User :

1. Intel Pentium Core 2 Duo

2. RAM 3 GB

3. Harddisk $250 \mathrm{~GB}$

Dengan menggunakan koneksi Switch HUB 10/100 Mbps.

\subsection{Perangkat Lunak}

Aplikasi klinik dibangun dengan menggunakan Tool Visual Basic .Net 2008 dan database yang digunakan adalah database MySql. Untuk sistem operasi yang digunakan di komputer server menggunakan Sistem Operasi Linux dan sistem operasi yang digunakan untuk komputer user adalah Sistem Operasi Window 7.

\subsection{Metode Pengembangan Sistem}

Metode pengembangan sistem yang digunakan merupakan metode prototipe evolusioner. Pendekatan evolusioner, suatu prototipe dibangun berdasarkan pada kebutuhan dan pemahaman secara umum. Prototipe yang ada kemudian dikembangkan dari bentuk awalnya atau dengan melakukan perubahan atas dasar kebutuhan yang tidak merubah desain secara keseluruhan. Prototipe juga didasarkan atas kebutuhan prioritas, yang terkadang diacu sebagai "chunking" pada pengembangan aplikasi [Janner, 2010].

\section{Pembahasan}

Dalam perancangan ini digunakan aplikasi jenis desktop untuk user karena dibutuhkan pembatasan komputer klien untuk akses ke komputer server. Dengan aplikasi desktop maka hanya komputer tertentu yang terinstal, yang dapat mengakses komputer server.

\subsection{Desain Sistem dan Tampilan} Antarmuka

Desain antarmuka sistem yang digunakan merupakan salah satu faktor penting dalam perancangan sistem. Selain untuk mempermudah dalam mengoperasionalkan, antarmuka juga dapat digunakan sebagai pembatas user dalam mengoperasionalkan sistem antarmuka yang berarti dapat digunakan sebagai salah satu pengaman sistem untuk menjaga kesalahan input dalam sistem, pembatasan kewenangan user dan mempermudah pemahaman user dalam kapasitasnya dalam organisasi.

Desain yang digunakan merupakan desain custom. Yang dimaksudkan custom 
dalam desain adalah custom dalam tampilan antarmuka untuk tiap user yang disesuaikan dengan jabatan dan fungsi masing-masing user pengguna. Penggunaan desain custom juga berhubungan dengan pemodelan yang akan digunakan.

Dalam perancangan antarmuka sistem yang digunakan, desain terbagi atas desain database dan program. Konsep yang digunakan adalah semua menu tampilan akan dimasukkan ke dalam database sehingga tampilan antarmuka yang tertampil merupakan hasil load dari database.

Desain database untuk antarmuka yang utama terdiri atas database untuk jabatan user dan custom menu. Berikut ilustrasi desain database untuk jabatan user dengan koderole sebagai primary key.

Tabel 1. Tabel Jabatan User

\begin{tabular}{|r|l|}
\hline koderole * & role \\
\hline 1 & Manajemen \\
2 & Front Office \\
3 & Kasir Dokter \\
4 & SPV \\
\hline 5 & admin \\
\hline
\end{tabular}

Dan gambar berikut merupakan ilustasi database untuk custom menu. Menuid merupakan kode pengelompokan dari menumenu yang ada dan header merupakan pengelompokan untuk antarmuka sistem dengan ' 0 ' sebagai header dan bilangan selain ' 0 ' merupakan kelompok atau child dari header.

Tabel 2. Tabel Menu

\begin{tabular}{|c|c|c|c|c|c|c|}
\hline menuid * & $t$ & menuname & formname & header & description * & imageid \\
\hline 2 & & Master & $\{$ null $\}$ & 0 & What this task do? & 2 \\
\hline 21 & & Dokter & FormDokter & 2 & What this task do? & 3 \\
\hline 22 & & Obat & FormInputObat & 2 & What this task do? & 4 \\
\hline 23 & & Master Tindakan & FormMasterTindakan & 2 & What this task do? & 5 \\
\hline 24 & & Pasien & FormPasien & 2 & What this task do? & 6 \\
\hline 25 & & Tarif & FrmMasterTarif & 2 & Setting Tarif & 2 \\
\hline 26 & & Master Bank & FormMasterBank & 2 & Master Bank & 5 \\
\hline 27 & & Master Kartu & FormMasterKartu & 2 & Master Kartu & 6 \\
\hline 3 & & Transaksi & $\{$ null $\}$ & 0 & What this task do? & 4 \\
\hline 31 & & Pendaftaran & FormDaftar & 3 & Meliputi pendaftaran pasien $b . .$. & 5 \\
\hline 32 & & Pembayaran & FormBayar & 3 & Pembayaran dari pendaftaran & 6 \\
\hline 33 & & Pengambilan Obat & FormTebusObat & 3 & What this task do? & 1 \\
\hline 34 & & Penjualan Obat & FormJualObat & 3 & What this task do? & 0 \\
\hline 35 & & Penambahan Obat & FormTambahobat & 3 & What this task do? & 3 \\
\hline 36 & & Entry Rekam Medis & FormRM & 3 & What this task do? & 6 \\
\hline 37 & & Posting Laporan & FrmGenerateRekap & 3 & Posting AllTransaksi To Report & 2 \\
\hline 4 & & Laporan & $\{$ null $\}$ & 0 & What this task do? & 7 \\
\hline 41 & & Laporan Penambah Obat & FormRptTambahObat1 & 4 & What this task do? & 2 \\
\hline 42 & & Histo Stok & FormRpthistoStok & 4 & What this task do? & 5 \\
\hline 43 & & Transaksi & FormRptTransaksi & 4 & What this task do? & 6 \\
\hline
\end{tabular}

Pemanggilan database dalam program dibantu dengan menggunakan prosedur dalam database MySql. Prosedure-prosedur tersebut sebagai berikut :

a. proc_z_getrole
Prosedur ini digunakan untuk memanggil jenis-jenis role/ jabatan.

b. proc_z_getrolemenu

Prosedur ini digunakan untuk memanggil jenis-jenis menu. 
Penggunaan prosedure tersebut digunakan untuk mempermudah program dalam mengakses data-data menu dalam database.

Program yang digunakan dalam perancangan sistem ini adalah program Visual Basic .Net 2008. Cara pemanggilan data dalam database dapat dijabarkan sebagai berikut :

a. Untuk menampilkan setting role/jabatan dapat digunakan perintah sebagai berikut:

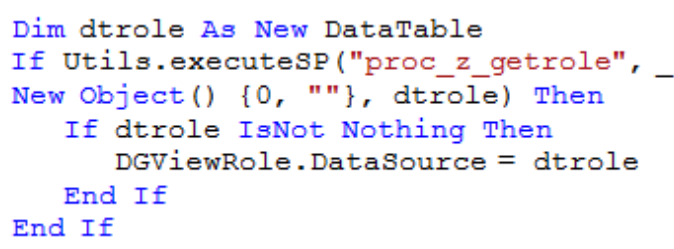

b. Untuk menampilkan setting menu dapat digunakan perintah sebagai beikut :

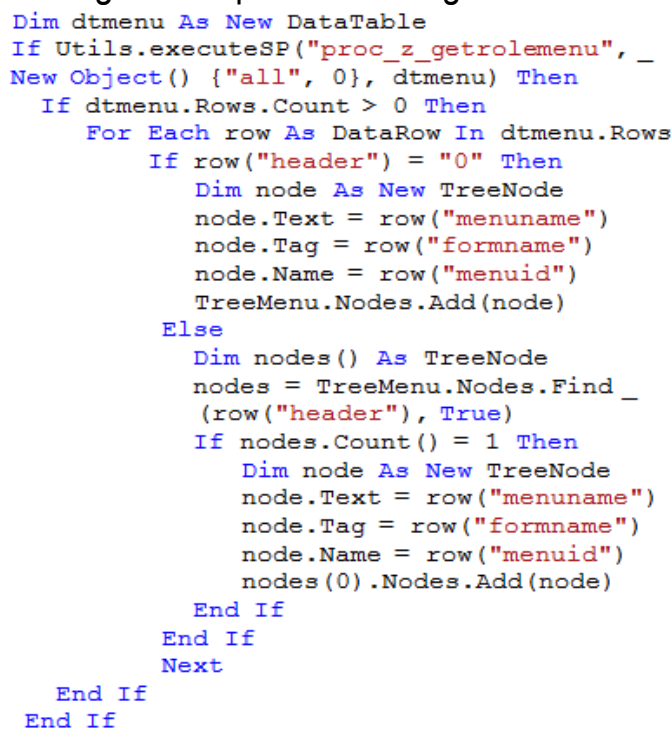

c. Untuk menampilkan menu utama :

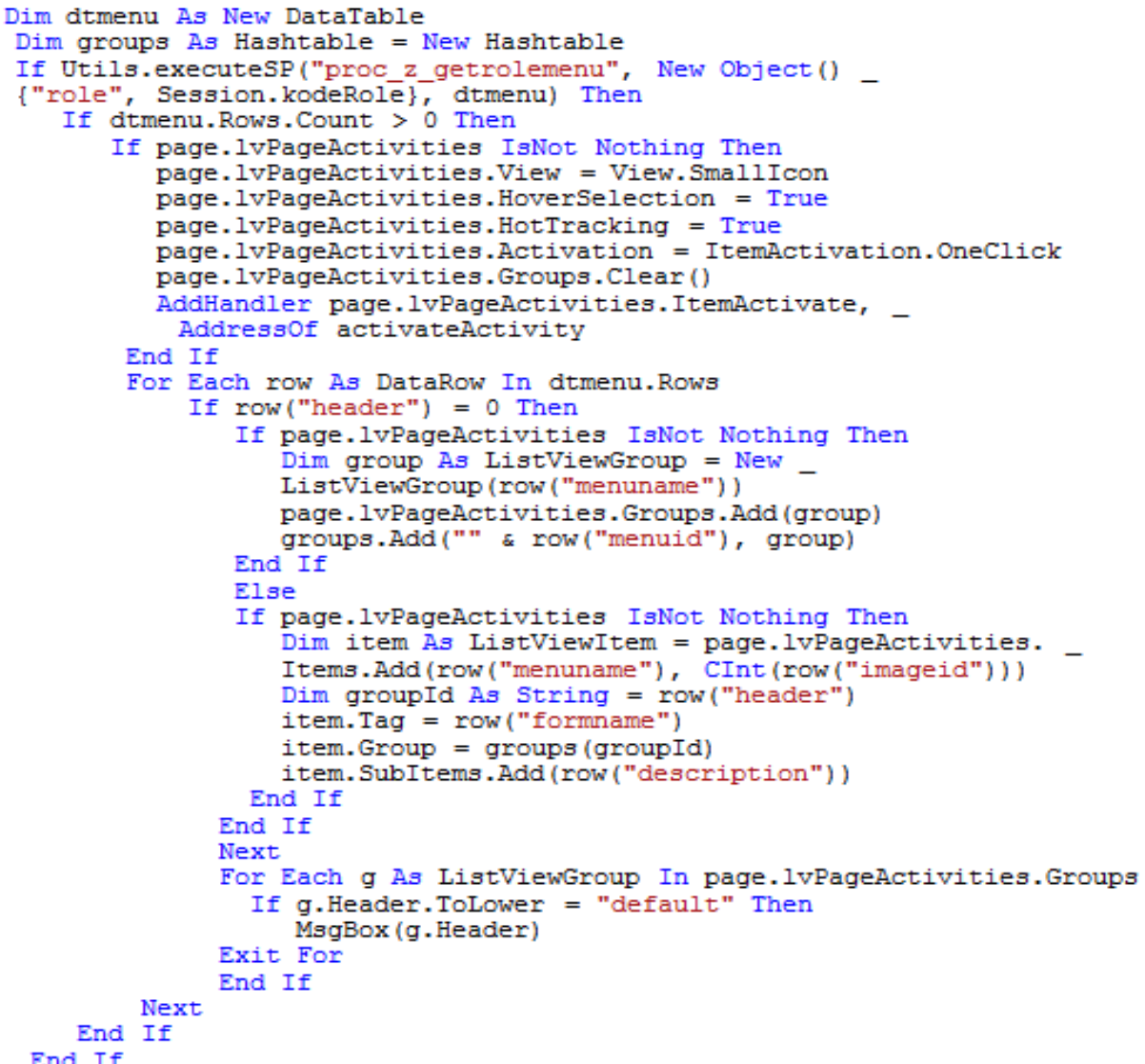

\subsection{Pengujian}

Pengujian dilakukan dengan menggunakan jaringan LAN 10/100 Mbps. Dan ilustrasi perancangan sistem yang diuji adalah sebagai berikut : a. Admin

Admin merupakan role tertinggi dalam sistem ini sehingga admin dapat mengakses keseluruhan menu yang ada. 
All Activities

Master -

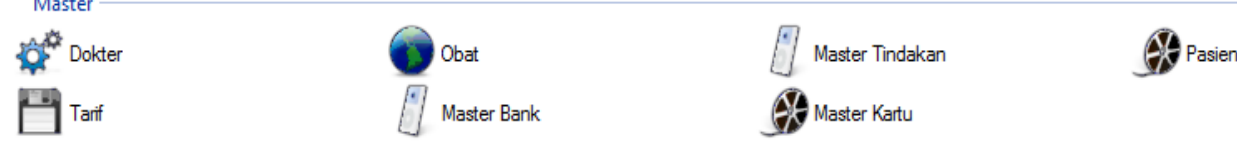

Transaksi

0 Pendaftaran

E Pembayaran

Penambahan Obat

Entry Rekam Medis

S Pengambilan Obat

Penjualan Obat

Laporan

Laporan Penambah Obat

$\theta$ Histo Stok

Stok Saat Ini

$\theta$ RekapTransaksi

$\theta$ Laporan Harian

Posting Laporan

E Laporan Bank

Etransaksi

tô Tindakan

E Laporan Rekap Dokter

(3) Penjualan

Capture Stoklni

Tools -

앙 Ubah Password

(3) Setting

0 Setting Menu

(3) Transaksi User

9 Daftar Ulang Tahun

Setting Password Report

\section{Gambar 2. Tampilan Menu Untuk User Admin}

b. Kasir

Kasir merupakan salah satu bagian dari

yang hanya menangani pembayaran dari tanggung jawab pekerjaan dari organisasi customer sehingga diberikan batasan hanya melayani transaksi pembayaran.

All Activities

Master

EPasien

Transaksi

Et Pembayaran

Laporan

$\theta$ Rekap Transaksi

Transaksi User

Tools

¿ी Ubah Password

\section{Gambar 3. Tampilan Menu Untuk User Kasir}

c. Front Office

Front Office merupakan salah satu bagian dari tanggung jawab pekerjaan dari organisasi yang hanya menangani pendaftaran dari customer sehingga diberikan batasan khusus pendaftaran untuk customer.

\section{All Activities}

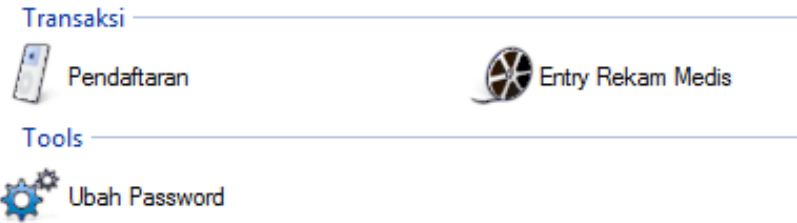

Gambar 4. Tampilan Menu Untuk User Front Office 
d. Supervisor

Supervisor merupakan salah satu bagian dari tanggung jawab pekerjaan dari organisasi yang menangani operasional organisasi sehingga supervisor akan mendapatkan tanggung jawab lebih besar daripada kasir ataupun front office.

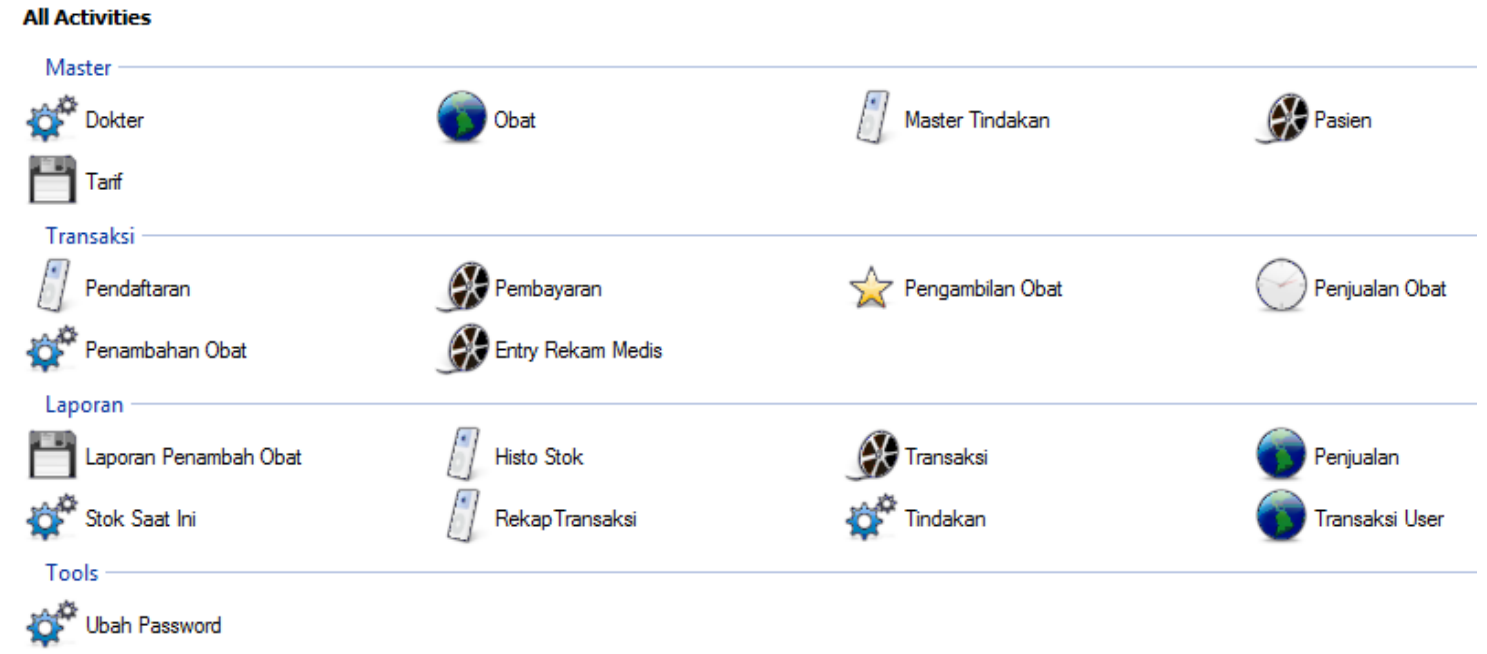

Gambar 5. Tampilan Menu Untuk User Supervisor

Dalam pengujian terlihat perbedaan tampilan dari tiap-tiap user untuk menu-menu yang tertampil. Dengan demikian pembatasan atas hak-hak akses tiap user dapat dilakukan.

\section{Kesimpulan}

Dalam perancangan ini, telah diujicobakan sistem antarmuka klinik kecantikan dengan memberikan hak akses yang berbeda kepada tiap-tiap user dan dapat ditampilan antarmuka yang berbeda-beda untuk tiap-tiap user. Dengan demikian sistem antarmuka yang dibangun dapat memberikan batasan hak akses kepada tiap-tiap user dan dapat digunakan sebagai pengaman sistem untuk menjaga dari kesalahan input dan pelaporan, dan mempermudah pemahaman user baru dalam kapasitasnya dalam organisasi.

\section{Daftar Pustaka}

Hough D., 1993, Rapid Delivery: An Evolution Approach For Application Development, IBM Systems Journal.

Roger S. Pressman, Ph. D, 2002, Rekayasa Perangkat Lunak Pendekatan Praktis (Buku Satu), Penerbit Andi, Yogyakarta.

Janner Simarmata, 2010, Rekayasa Perangkat Lunak, Penerbit Andi, Yogyakarta

Kenneth C. Laudon, Jane P. Laudon, 2005, Sistem Informasi Manajemen Mengelola Perusahaan Digital, Penerbit Andi, Yogyakarta.

Bambang Hariyanto Ir. MT., 2004, Rekayasa Sistem berorientasi Objek, Penerbit Informatika, 